\title{
TURRó, S., Fichte. De la Consciència a l'Absolut
}

\section{Edgar Maraguat}

\section{OpenEdition \\ Journals}

Edición electrónica

URL: http://journals.openedition.org/ref/312

DOI: $10.4000 /$ ref.312

ISSN: 2258-014X

Editor

EuroPhilosophie Editions

\section{Referencia electrónica}

Edgar Maraguat, " turRó, s., Fichte. De la Consciència a l'Absolut », Revista de Estud(i)os sobre Fichte [En línea], 4 | 2012, Publicado el 01 septiembre 2012, consultado el 23 septiembre 2020. URL : http:// journals.openedition.org/ref/312 ; DOI : https://doi.org/10.4000/ref.312

Este documento fue generado automáticamente el 23 septiembre 2020

(c) EuroPhilosophie 


\title{
TURRó, S., Fichte. De la Consciència a l'Absolut
}

\author{
Edgar Maraguat
}

\section{REFERENCIA}

TURRÓ, S., Fichte. De la Consciència a l'Absolut, Badalona (Barcelona): Òmicron, 2011, 274 pp., ISBN 9788492544981

1 Ha escrito el profesor Turró una introducción a la filosofía de J. G. Fichte para iniciados y legos. No hay muchas obras, ni en catalán ni en castellano, con las que comparar la suya. Los tres elementos distintivos de su monografía, los más notables, son, primero, una atención indivisa al conjunto de la producción de Fichte (publicada o póstuma, científica o popular, tanto a la que se ocupa de la fundamentación de la conciencia y el saber como a la que trata de las costumbres, la economía, la política); segundo, la decisión de extirpar a Fichte del Bildungsroman del Idealismo Alemán; y, tercero, la tenacidad con que se le cede la palabra al filósofo para que se explique "por sí mismo". En todo caso, ningún precedente ensombrece los logros de este intento. La erudición, ecuanimidad y elocuencia de Turró producen un texto fluido, bien armado, bien organizado, muy informativo, útil para estudiantes, para historiadores y para filósofos profesionales. Me atrevo a decir que el desaparecido profesor Valls Plana, a quien está dedicado el libro, de grado hubiera reconocido su magisterio en este resultado.

2 Las tres caras de la metodología del ensayo a las que me refiero -la presentación unitaria de toda la obra, el desplazamiento de Schelling y Hegel, no tanto de Kant, a un borroso trasfondo del desarrollo del pensamiento de Fichte, el sinnúmero de citassirven a una intención apologética. Trata Turró de librar a su filósofo de la estimación de una mera figura crepuscular, "subalterna”, de transición, que ha sido habitual: como epígono de Kant o, acaso, como precursor de Hegel.

El propósito está sobradamente justificado. El panorama de estudios fichteanos con el que la obra se remata (ocurrencia ésta encomiable, servicial y digna de imitación) 
proporciona una justificación indirecta, pues lo componen exclusivamente referencias a estudios alemanes, italianos y franceses (excepción hecha de un libro de J. Cruz y otro de B. Navarro). La insinuación viene a ser que, entre nosotros, Fichte está aún por descubrir y aquilatar. La directa la aportan las méritos filosóficos del autor del Basamento de toda la Doctrina de la Ciencia: los adquiridos tratando de emancipar a la 'filosofía crítica' de sus ambigüedades metafísicas o dogmáticas, tratando de proporcionar el concepto adecuado de acción in fieri (el concepto, en fin, de causa primera, una causa cuya mera posibilidad Kant tachó en la primera Crítica de incomprensible), elevando la acción a Prinzip de la filosofía, supeditando a ella el concepto mismo de 'ser' (un movimiento que será determinante de la historia de la filosofía posterior, de sus muchos voluntarismos y pragmatismos), secularizando el descubrimiento de la libertad que Kant había ligado a la conciencia introspectiva de una ley moral inscrita en el corazón y, por cierto, secularizándolo a base de vincular el reconocimiento de la propia libertad al de otras libertades (dicho de otro modo, la subjetividad agente a lo que hoy es denominado 'intersubjetividad').

Pero aun cuando esté justificado ese deseo, ¿es la metodología, es la exposición de la filosofía de Fichte fuera de la trama que forman las discusiones sobre la filosofía trascendental con o de Schelling y Hegel, a vueltas con y a costa de Kant, un medio eficaz para la vindicación que se busca? Turró piensa que sí (las inspiraciones filosóficas del devenir de Fichte que él destaca son, sobre todo, las iniciales -Kant, Reinhold, Schulze, Schiller- y luego la 'polémica sobre el ateísmo' y el papel en torno a ella de Jacobi). Otros estudiosos del periodo opinan que no. ¿Por qué piensa Turró lo contrario? Dos razones se nos ofrecen en la obra. Por un lado, el entusiasmo que supuestamente tendría que despertar, entonces y ahora, un sistema que permanece dentro de los límites de una exploración de la conciencia de tenor trascendental, que parte del hecho de la conciencia, el hecho del auto-reconocimiento y el hecho del dato sensible (cf. pp. $63,74,82,146,163)$. Y, por otro lado, la atribución en la página 14 de una divina inmortalidad, de la inmarcesible actualidad de la philosophia perennis, al pensamiento de Fichte (que algún lector relacionará con la negación 'idealista' del tiempo; cf. pp. 108 y 217). Son estos principios interpretativos los que explican la fotografía plana, quemada, que en el texto asoma, de Schelling, el filósofo de la identidad (cf. pp. 132 s.), quien queda rebajado a divulgador o discípulo de Fichte, y Hegel, el idealista absoluto (cf. pp. $47,162,211)$.

5 Sin embargo, el profesor Turró piensa también que el interés de la publicación procede de que la obra de Fichte se inserta en una tradición "de la que formamos parte" y sin la cual "no se puede entender nada de lo que somos" (es más, llama la atención en una ocasión sobre la conciencia que tuvo el propio Fichte del carácter "dialéctico", por "separación de oposiciones", por contraposición a alternativas, de la exposición científica; p. 47). Por eso, y a la vista del éxito al que, por pericia, conocimiento, talento y experiencia, conduce la empresa de redactar un Fichte par lui-même, se suscita en uno el deseo de que, algún día, él mismo se proponga sumar a esta exposición, con el objeto de una leve corrección, un proporcional Fichte im Kontext o, incluso, un personal Von Kant bis Hegel (o, mejor aún, Von Kant bis Schelling). 


\section{AUTORES}

\section{EDGAR MARAGUAT}

Universitat de València 